\title{
Investigação em sala de aula: o desafio de professores do Projeto UCA no Estado do Pará
}

\author{
Cintya Ribeiro de Oliveira ${ }^{1}$, Jecy Jane dos Santos Jardim ${ }^{1}$, Maria Elisabette B. \\ Brito Prado ${ }^{1}$, Nielce Lobo da Costa ${ }^{1}$
}

${ }^{1}$ Universidade Bandeirante Anhanguera - Rua Maria Cândida, 1813 - $4^{\mathrm{o}}$ andar Vila Guilherme - São Paulo/SP - Brasil - CEP: 020171-013

cintya.ily@gmail.com, jecyjs@gmail.com, nielce.lobo@gmail.com, bette.prado@gmail.com

\begin{abstract}
This articleisan experience report. This is thechallenge of buildinga proposal forcontinuing education of teacherswhose main objectivewasthe awakeningof possibilitiesof working withstudentsina pedagogical approachbased on research andaided bytechnological resourcesavailablein the school, more specifically, the laptop's educational UCA project. Theplanning of thishappenedin atrainingworkshopofferedto teachers, futuremultipliers, school representativesawarded theUCA Projectin Pará.
\end{abstract}

Resumo. Este artigo é um relato de experiência. Trata-se do desafio de construir uma proposta de formação continuada de professores cujo objetivo principal fosse o despertar de possibilidades de trabalho com os alunos sob uma abordagem pedagógica baseada na investigação e auxiliada pelos recursos tecnológicos disponíveis na escola, mais especificamente, o laptop educacional do Projeto UCA. O planejamento desta formação aconteceu em uma oficina ofertada a professores, futuros multiplicadores, representantes de escolas contempladas com o Projeto UCA no Estado do Pará.

\section{Introdução}

Mudanças no fazer pedagógico docente são exigidas a cada momento, pois a vida na escola está em constante transformação. A chegada do laptop educacional nas escolas contempladas com o Projeto Um Computador por Aluno - UCA tornou-se um divisor de águas e exige que gestores e professores repensem toda a estrutura escolar.

Segundo Almeida e Mendes (2011, p.50), o laptop educacional conectado facilita e incentiva a pesquisa, ou seja, o aluno vai à procura de informações no momento em que elas são significativas para ele. Sendo assim, o aluno muda de comportamento e começa a experimentar a aprendizagem por investigação. Muda-se, também, o papel do professor que agora será

o de organizar e criar situações que propiciem ao aluno novas experiências, com a perspectiva de oportunizar o desenvolvimento da autonomia na busca de informações, a liberdade de buscar novos caminhos para aprender, a capacidade de trabalhar em grupo e de tomar iniciativa para enfrentar novas situações. (MENDES; ALMEIDA, 2011, p.52) 
Considerando estas e outras mudanças referentes ao uso do laptop educacional em sala de aula e pensando nas possíveis dificuldades que os docentes possam ter, pretendemos com este artigo dar a conhecer os caminhos que trilhamos ao propor para um grupo de professores representantes de escolas UCA localizadas no Estado do Pará, através de uma oficina de estudo, a construção de uma proposta de formação continuada que ajudasse os docentes a desenvolver atividades pedagógicas que tivessem uma abordagem baseada em investigação.

\section{Atividade de Investigação: o professor diante de uma nova perspectiva de ensino}

A elaboração de atividades investigativas requer especial atenção do professor, uma vez que ao pensar em tais atividades deve-se ter em conta que o aluno seja capaz de discutir com seus colegas, explicar seu ponto de vista, refletir sobre suas conjecturas, relatar suas descobertas. Estas ações mediadas pelo professor darão a estas atividades o caráter de investigação científica.

Contudo, concordamos com Ponte (2006) quando ele afirma que

(...) em contexto de ensino e aprendizagem, investigar não significa necessariamente lidar com problemas muito sofisticados, na fronteira do conhecimento. Significa, tão-só, que formulamos questões que nos interessam para as quais não temos resposta pronta, e procuramos essa resposta de modo, tanto quanto possível, fundamentado e rigoroso (p.9).

Ao propor que os alunos mergulhem no desenvolvimento de atividades investigativas, o professor os convida a quebrar o paradigma que envolve aulas tradicionais, não que estas sejam menos importantes, mas a mudança de estratégia poderá fazer com que os alunos saiam da passividade e participem de seu próprio processo de aprendizagem. O aluno será instigado. Ele precisará sair em busca de suas respostas, precisará tomar decisões a fim de solucionar seus mistérios. Deste modo, fazse necessário que a atividade de investigação proposta tenha algum sentido para ele.

Os professores que enfrentam o desafio de mudar sua prática pedagógica buscam solucionar questões do tipo: como planejar uma aula que tenha uma abordagem pedagógica baseada na investigação? De modo geral, uma aula com atividades de investigação está dividida em três etapas: introdução da tarefa, desenvolvimento do trabalho e discussão final (CHRISTIANSEN\&WALTHER, 1986).

Iniciar o trabalho com atividades investigativas, principalmente se alunos e/ou professoresainda não têm esse tipo de vivência, nos impele a seguir essas três fases. Assim, o ponto de partida será pensar como apresentaremos a atividade. Pérez e Castro (1996) apontam dez aspectos importantes para o planejamento de atividades deste tipo, entre eles ressaltamos "potencializar a dimensão coletiva do trabalho científico" (p.157), e enfatizam que estes aspectos não constituem de forma alguma uma receita a ser seguida, mas um lembrete da riqueza do trabalho científico.

Insistimos en que los aspectos contemplados no constituyen ningún algoritmo, ningún intento de ahormar la actividad científica en unos "pasos" o "etapas", sino un recordatorio de la riqueza del trabajo científico (PÉREZ; CASTRO, 1996, p. 157). 
Nesta fase inicial a tarefa a ser proposta pelo professor deve ser colocada aos alunos de forma clara e tranquila. O professor pode decidir, por exemplo, se fará uma contextualização antes da atividade, se realizará leituras que elucidem o que será pedido ou se disponibilizará a tarefa por escrito. O importante é que o aluno não fique desnorteado, buscando sem sucesso uma maneira de começar seu trabalho. Não podemos deixar que ele seja desmotivado. E se ocorrer de alguém não conseguir ir adiante, o professor sempre pode dar "pistas" (e não respostas) que ajudem a compreender esta etapa da aula.

Ponte (1999), em seu artigo sobre atividades de investigação, apresenta o exemplo de uma professora introduzindo a tarefa para alunos do $5^{\circ}$ ano:

\begin{abstract}
(...) a professora optou por apresentar a tarefa oralmente e por escrito. Como se tratavam de alunos sem experiência de trabalho de cunho investigativo, começou por ler as questões propostas na ficha, explicou o significado de algumas palavras (por exemplo, a palavra conjectura, mas que não ficou completamente percebida nesta altura) e formulou algumas questões tais como: Qual o significado da palavra cubo? tendo sempre em conta a preocupação de não dar informação a mais nem a menos (p.6).
\end{abstract}

No desenvolvimento do trabalho, segunda etapa da aula, deseja-se que o aluno assuma uma postura investigativa, ou seja, que ele questione, argumente, reflita sobre a atividade que tem nas mãos. Neste sentido, cabe ao professor o papel de mediador, é ele quem vai estimular a interação com os colegas, a defesa de opiniões, propor novos questionamentos e ajudar os alunos a organizar suas ideias. Durante esta fase da aula o professor pode ser bastante solicitado e nestes momentos deve estar atento para compreender, por exemplo, quando o aluno precisa apenas que ele dê sustentabilidade a seus pensamentos ou quando ele está caminhando de forma a levá-lo para longe dos objetivos da aula e, neste caso, é seu dever instigá-lo de modo a retomar o foco e a linha de raciocínio.

A etapa final da aula é o momento de socialização dos resultados. Nesta fase o professor deve incentivar a comunicação entre seus alunos. Talvez aconteça de alguns ficarem tímidos ou desconfortáveis para falar, mas o professor deve cuidar para que todos exponham seus resultados. No momento da socialização o professor deve valorizar todas as produções. $\mathrm{O}$ aluno, ao ouvir o colega, poderá encontrar-se diante de possibilidades ou caminhos que não tenha cogitado e isso pode ocasionar confronto de ideias, mas todos devem ser estimulados à discussão crítica e enriquecedora do conhecimento.

Fonseca, Brunheira e Ponte (1999) recorrem a Bishop e Goffree (1986) para dizer que "a aprendizagem não resulta simplesmente da actividade, mas sim da reflexão sobre a actividade. Deste modo, é fundamental, proporcionar aos alunos momentos onde possam pensar e, sobretudo, reflectir sobre a actividade realizada" (p.9).

A seguir apresentamos a oficina "Uso do laptop educacional em atividades investigativas" que foi ofertada para os professores das escolas UCA no Estado do Pará. A proposta era que esses representantes vivenciassem uma atividade de caráter investigativo com uso das tecnologias, refletissem sobre suas potencialidades e recontextualizassem em suas escolas. 


\title{
3- A Oficina "Uso do laptop em atividades investigativas"
}

O trabalho com atividades investigativas pode ser auxiliado pelo uso das Tecnologias Digitais de Informação e Comunicação - TDIC. Ao propor a oficina "Uso do laptop educacional em atividades investigativas", pretendíamos que os professores multiplicadores, representantes das escolas UCA, discutissem como poderiam ajudar os professores a desenvolver em suas aulas uma abordagem pedagógica baseada em investigação tendo em vista que a escola dispunha de laptops educacionais conectados na modalidade 1:1. Em outras palavras, pretendíamos que os multiplicadores construíssem uma proposta de formação continuada que ajudasse os docentes a desenvolver o trabalho com atividades investigativas usando o laptop educacional do projeto UCA.

A oficina foi desenvolvida em 2012 na cidade de Belém, no estado do Pará e contou com a presença de 20 participantes: 02 representantes da Universidade Federal do Pará - UFPA, 02 representantes da Secretaria de Educação - SEDUC/PA e 16 professores multiplicadores dos Núcleos de Tecnologia Educacional - NTE. Usamos como metodologia de trabalho a pesquisa-ação, pois todos os envolvidos na oficina estavam vivendo um processo de desconstrução e discutiam possibilidades de renovação de suas práticas escolares. Thiollent (1985) afirma que

\begin{abstract}
A pesquisa-ação é um tipo de pesquisa social que é concebida e realizada em estreita associação com uma ação ou com a resoluçãode um problema coletivo e no qual os pesquisadores e os participantes representativos da situação da realidade a ser investigada estão envolvidos de modo cooperativo e participativo (p. 14).
\end{abstract}

\section{1 - Refletindo sobre o caráter investigativo de atividades propostas aos alunos}

A motivação inicial do trabalho com os professores foi o conhecimento que eles detinham sobre investigação. Começamos por fazer as seguintes perguntas: O que significa investigar? E educar pela pesquisa?Após ouvirmos as respostas fizemos uma abordagem reflexiva sobre o assunto. Citamos Moraes (2004) para dizer que

\footnotetext{
Educar pela pesquisa tem como objetivo incentivar o questionamento dentro de um processo de reconstrução do conhecimento. Esse processo pode ser entendido como a produção de um conhecimento inovador que inclui interpretação própria, formulação pessoal, saber pensar e aprender a aprender.Dessa forma, educar pela pesquisa é ir contra a cópia, a condição de objeto e a manipulação do aluno (p. 88).
}

Em certos momentos tivemos opiniões divergentes, pois alguns professores questionaram o rigor do trabalho com a pesquisa no ensino básico. Isto enriqueceu a discussão, pois conseguíamos perceber nos professores o exato momento do desequilíbrio (Piaget, 1977). Emergia no calor da discussão o fato de que na maioria das vezes a "pesquisa" era usada como forma de avaliar o aluno, mas não havia qualquer acompanhamento docente e sem a devida preocupação com o produto, objeto de "investigação".

Valente (2012) comenta que 
Infelizmente, no contexto escolar, a "pesquisa" tem sido interpretada e usada para substituir provas ou outros meios de avaliar os alunos, ou "fazer um trabalho de pesquisa" que se resume na criação de grupos de alunos para levantar informação sobre um determinado assunto e relatar em um texto a ser entregue para o professor. (p.82)

Ao serem questionados sobre como eram conduziam as atividades de pesquisa na escola os professores reagiram imediatamente, e suas respostas vinham numa tentativa de defender sua prática pedagógica: "os alunos não sabem pesquisar! Se a gente pede uma pesquisa, eles vão só copiar e colar da Internet (Prof. A, áudio)".

À medida que conduzíamos as discussões sobre educar pela pesquisa íamos percebendo nos professores pequenos sinais de mudança. Os professores assimilavam os novos conceitos sobre pesquisa e investigação em sala de aula e aos poucos iam sugerindo estratégias para melhorar a abordagem de seus projetos. Começamos então a conversar sobre o caráter investigativo das atividades propostas aos alunos tomando como base as etapas mencionadas por Christiansen e Walther (1986), que são: introdução da tarefa, desenvolvimento do trabalho e discussão final.

\section{2 - Propostas de atividades com abordagem pedagógica baseada em investigação}

Nesta etapa da oficina de estudo os professores levantaram questões referentes ao dia-adia na escola. Dentre elas escolhemos explanar as seguintes:

1- Como identificar uma atividade com caráter investigativo?

2- E os laptops? Como colocá-los neste novo cenário sem perder o foco?

3- Como deveriam trabalhar com o professor quando fossem replicar a oficina?

4-Como ficariam os conteúdos nessa nova proposta?

5- O que dizer aos gestores?

Começávamos a construir a proposta de formação continuada que seria desenvolvida nas escolas. Como estratégia de trabalho optamos por apresentar duas metodologias que poderiam ajudar no desenvolvimento de atividades com investigação auxiliadas pelo uso do laptop educacional: pedagogia de projetos e WebQuest.

$\mathrm{Na}$ atividade com projeto, após apresentar a metodologia, sugerimos que os professores se dividissem em 03 grupos e escolhessem um tema fosse de seu interesse. Em seguida pedimos que levantassem uma questão para a qual não tivessem a resposta. Sugerimos que a partir desse momento eles elencassem as dúvidas e as certezas que tinham sobre o tema que escolheram e partissem em busca de respostas para a questão de investigação. Ao final do tempo estipulado para esta atividade, iniciamos a socialização dos resultados e cada grupo pode apresentar seu trabalho. Nesta atividade os professores deveriam usar o laptop educacional para ajudá-los com suas pesquisas e com a organização de seus resultados.

O trabalho com a WebQuest fluiu de forma semelhante. Apresentamos a metodologia e sugerimos que desenvolvessem a atividade proposta e publicassem seus resultados. Nesta atividade o uso do laptop tornou-se imprescindível, uma vez que a conclusão da atividade dependia da conexão com a Internet.

A opção por projetos como sugestão de atividades justifica-se porque os professores já adotam esta prática nas escolas. O diferencial está na forma como estes projetos serão colocados aos alunos e como as tarefas serão conduzidas. 
(...) ao propor uma atividade de investigação, deve-se discutir a importância do tema em estudo. Uma orientação investigativa pressupõe o envolvimento dos estudantes em uma tarefa cuja finalidade e sentido estejam claros para eles. A discussão da importância do tema proposto contribui para que os estudantes comecem a formar uma concepção preliminar da situação problemática, permitindo, assim, a realização de uma análise qualitativa que lhes ajude a estabelecer limites para a situação em questão e transformá-la em um problema preciso. (SÁ et al, 2007)

\section{3 - A oficina de estudo na opinião dos professores multiplicadores}

A viabilidade do trabalho pedagógico baseado em investigação muito nos preocupava e consideramos de extrema importância ouvir a opinião dos professores multiplicadores das escolas UCA no Estado do Pará.

Com relação à proposta de atividades todos concordaram com seu valor e importância no trabalho com os alunos. Os professores entenderam as principais diferenças entre o ensino tradicional e o ensino pela pesquisa mediado por computador.

As dificuldades estariam, na opinião deles, na praticidade e na logística deste trabalho. As escolas que estavam representando naquele momento eram, em sua maioria, da zona rural. Nestas escolas o maior problema estava em estabelecer conexão com a Internet. Havia também escolas cujos computadores foram roubados e que, portanto, a modalidade 1:1 já não acontecia, escolas multisseriadas, escolas com problemas de gestão, com laptops estragados, etc.

Os multiplicadores em sua avaliação da oficina não viam dificuldades em realizar a formação continuada, mas concordavam que os professores não teriam condições de por em prática esse aprendizado. Não usando os laptops educacionais!

\section{4- Considerações que julgamos importantes acerca deste trabalho}

Ao planejarmos a oficina de estudo queríamos atender aos professores que, sempre que podiam, solicitavam aos NTE formações para o uso dos laptops em suas aulas. Pensamos que podíamos desenvolver uma ação que favorecesse o estudo de novas metodologias de ensino e ainda retirar dos armários os computadores, há muito tempo lá esquecidos.

Em nossa opinião atingimos parcialmente nosso objetivo. A semente foi lançada, os multiplicadores entenderam a proposta da formação continuada, desenharam um esquema para ser melhorado e aplicado em suas escolas e aceitaram o desafio de replicar a experiência.

Tivemos notícias de alguns multiplicadores que fizeram a formação em suas escolas, mas que ainda não colheram os frutos. Segundo eles "os professores encontram-se desmotivados para enfrentar tantos problemas para por em prática um projeto" (Prof. B, 2012, e-mail)

Ficamos preocupadas com a realidade das escolas envolvidas no Projeto UCA. Compreendemos perfeitamente a posição dos multiplicadores e entendemos seus questionamentos. Realmente desenvolver investigação em sala de aula usando o laptop educacional nas condições apresentadas pelos professores não deve ser tarefa das mais 
fáceis. Contudo, em nossa opinião, o grande desafio da educação é romper barreiras em prol de qualidade. Os laptops, conectados ou não, já fazem parte do acervo da escola e precisamos fazer um bom uso dessa ferramenta.

Acreditamos que os multiplicadores têm condições de estimular seus colegas professores e incentivá-los a realizar atividades com investigação em sala de aula, mas para isto é necessário investir na formação continuada do professor, a qual pode ocorrer também pelo desenvolvimento de grupos de estudos na escola com a participação dos multiplicadores. O professor precisa ter oportunidade de desenvolver novas práticas e de refletir sobre elas, analisar suas potencialidades em termos de favorecer ao aluno atitudes investigativas, de autoria e de autonomia para caminhar em busca de novas e significativas aprendizagens.

\section{REFERÊNCIAS}

ALMEIDA, M. E. B.; MENDES, M. (2011) Utilização do laptop educacional em sala de aula. In: ALMEIDA, M. E. B.; PRADO, M. E. B. B. (Org.) O computador portátil na escola: mudanças e desafios nos processos de ensino e aprendizagem. São Paulo: Avercamp. p.49-59.

BISHOP, A.; GOFFREE, F. (1986). Classroom organization and dynamics. In B. Christiansen, A. G. Howson, \& M. Otte (Eds.), Perspectives on mathematics education (pp. 309-365). Dordrecht: D. Reidel.

CHRISTIANSEN, B., WALTHER, G. (1986) Task and activity. In CHRISTIANSEN, B.; HOWSON A. G.; OTTE, M. (Eds.) Perspectives on mathematics education Dordrecht: D. Reidel. p. 243-307

FONSECA, H.; BRUNHEIRA, L.; PONTE, J. P. (1999) As actividades de investigação, o professor e a aula de Matemática. Actas do ProfMat 99. Lisboa: APM.

MORAES, M. C. (2004) Do ponto de interrogação ao Ponto: a utilização dos recursos da Internet na educação pela pesquisa. In Moraes, Roque \& Lima, Valderez M. do (org.), Pesquisa em Sala de Aula: tendências para a educação em novos tempos. 2 Ed. Porto Alegre: EdiPUCRS.

PONTE, J. P.; BROCARDO, J; OLIVEIRA, H. (2006) Investigações matemáticas na sala de aula. 1ed., $2^{\mathrm{a}}$ reimp. Belo Horizonte: Autêntica. 151p.

PÉREZ G. D.; CASTRO V. P.(1996) La orientaçión de las práticas de laboratório como investigación: un ejemplo ilustrativo. Enseñaza de las Ciências, 14 (2), 155-163

PIAGET, J. (1977) O Desenvolvimento do Pensamento: Equilibração das Estruturas Cognitivas. Lisboa: Publicações Dom Quixote.

SÁ, E.F; PAULA, H.F.; LIMA, M.E.C.C. e AGUIAR JÚNIOR, O.G; (2007). As características das atividades investigativas segundo tutores e coordenadores de um curso de especialização em ensino de ciências. In Atas do VI ENPEC - Encontro Nacional de Pesquisa em Educação em Ciências, Florianópolis, SC. 
II Congresso Brasileiro de Informática na Educação (CBIE 2013)

Workshops (WCBIE 2013)

THIOLlENT, M. (1985).Metodologia da Pesquisa-Ação. São Paulo: Cortez.

VALENTE, J. A.; MARTINS, M. C.; BARANAUSKAS, M. C. C.(2012) Laptop Educacional e a educação baseada na investigação: do estudar fatos científicos para fazer ciência. In: SAMPAIO, F. F.; ELIA, M. F. (Org) Projeto um computador por aluno: pesquisas e perspectivas. Rio de Janeiro: NCE/UFRJ. p.79-90. 